\title{
Roughness Evaluation of the Machined Surface at Interrupted Cutting Process
}

\author{
Sarka Malotova ${ }^{1}$, Robert Cep ${ }^{1}$, Lenka Cepova ${ }^{1}$, Jana Petru ${ }^{1}$, Dana Stancekova ${ }^{2}$, Ladislav Kyncl ${ }^{1}$, Michal Hatala ${ }^{3}$ \\ ${ }^{1}$ Faculty of Mechanical Engineering, VŠB - Technical University of Ostrava. 17. Listopadu 15/2172, Ostrava. Czech \\ Republic.E-mail: sarka.malotova.st@vsb.cz, robert.cep@vsb.cz, lenka.cepova@ vsb.cz, ladislav.kyncl.st@vsb.cz \\ ${ }^{2}$ Faculty of Mechanical Engineering, Univerzity of Žilina, Univerzitna 1, 010 26, Zilina. Slovakia. E-mail: dana.stance- \\ kova@fstroj.uniza.sk \\ ${ }^{3}$ Faculty of Manufacturing Technology with seat in Presov, Technical University in Kosice, Bayerova 1, 08001 Prešov, \\ E-mail: michal.hatala@tuke.sk
}

The article deals with the evaluation of the roughness of the machined surface, steel ISO C45 and ISO 11CrMo910 after machining at interrupted cutting conditions. A regular interrupted cut and irregular interrupted cut can have significant effect on the resulting surface of components. Parameters of roughness were measured on the slats, which was machined with using the interrupted cutting simulator. The slats were gradually machined - 4, 3, 2 and 1 slat for getting irregular interrupted cut. Selected parameters of roughness which were tested; Ra - an average arithmetic deviation, $\mathrm{Rq}$ - an average quadratic deviation and $\mathrm{Rz}$ - the maximum height of the roughness profile. Experiment took place in cooperation with Faculty of Mechanical Engineering of VSB - TU Ostrava and Faculty of Mechanical Engineering of ZU Zilina - machining in the laboratories of ZU Zilina, Slovak Republic.

Keywords: surface roughness, interrupted cutting, slat test

\section{Acknowledgment}

This work was supported by the European Regional Development Fund in the IT4Innovations Centre of Excellence project CZ.1.05/1.1.00/02.0070, by Education for Competitiveness Operational Programme financed by Structural Founds of Europe Union in project Integrita CZ.1.07/2.3.00/20.0037 and by Student Grant Competitions SP2015/116 and SP2015/129 financed by the Ministry of Education, Youth and Sports and Faculty of Mechanical Engineering VŠBTechnical University of Ostrava.

\section{References}

[1] NESLUŠAN, M. et al. (2007). Experimentálne metódy v trieskovom obrábaní. 1. vyd. Žilina: Žilinská univerzita v Žiline, 349 s. ISBN 978-80-8070-711-8

[2] TICHÁ, Š. (2004). Strojírenská metrologie: část 1. 1. vyd. Ostrava: Vysoká škola báňská - Technická univerzita, 104 s. ISBN 80-248-0671-1. Dostupné také z: http://books.fs.vsb.cz/StrojMetro/strojirenska-metrologie.pdf

[3] NOVÁK, M. (2012). Surface with High Precision of Roughness after Grinding. Manufacturing Technology, Vol. 12, No. 12, pp. 66-70. ISSN 1213-2489.

[4] EVERS, D. (2009). Interrupted Turning: Innovations in turning tooling combat the challenges of interrupted cutting. Canada's Metalworking \& Fabricating Technology Magazine., č. 9. Dostupné z: http://www.cimindustry.com/article/tooling/interrupted-turning

[5] SHAW, M. C. (2005). Metal Cutting Principles. 2nd edition. New York : Oxford University Press, 651. p. ISBN 0-19-514206-3.

[6] ČSN EN ISO 4287. Geometrické požadavky na výrobky (GPS) - Struktura povrchu: Profilová metoda - Termíny, definice a parametry struktury povrchu. 1999.

[7] MALOTOVÁ, Š. (2015). Vliv technologických parametrů v závislosti na povrchová napětí při obrábéní na simulátoru přerušovače ř zu. Ostrava, 2015. Diplomová práce. VŠB - TU Ostrava.

[8] ČEP, R. (2010). Návrh a ověření metodiky testování řezných nástrojů při přerušovaném řezu. Ostrava, 2010.119 s. Habilitační práce. Vysoká škola báňská - Technická univerzita Ostrava.

[9] CEP, R., JANASEK, A., PETRU, J., CEPOVA, L., CZAN, A., VALICEK. (2013). Hard machinable machining of cobalt-based superalloy. Manufacturing Technology, Vol. 13, No. 2, pp. 142-147. ISSN 1213-2489.

[10]Pokrok v měření a hodnocení struktury povrchu. MM priomyslové spektrum. 2001, (4). Dostupné také z: http://www.mmspektrum.com/clanek/pokrok-v-mereni-a-hodnoceni-struktury-povrchu.html

[11]BÁTORA, B., VASILKO, K. (2000). Obrobené povrchy: technologická dedičnost', funkčnost'. Trenčín: Trenčianska univerzita, 183 s. ISBN 80-889-1419-1. 
[12]VASILKO, K., MACUROVÁ, A (2012). Two local extremes of cutting speed. Manufacturing Technology, Vol. 12, No. 12 , pp. 86 - 89. ISSN 1213-2489

[13]PFEILER, P. (2012). Metodika testování keramických řezných nástrojů při přerušovaném řezu. Ostrava, 147 s. Disertační práce. Vysoká škola báňská - Technická univerzita Ostrava.

[14] DAVIM, J. Paulo, editor. Surface integrity in machining. London: Springer, 2010. ISBN 978-184-8828-742.

[15]KOURIL, K., CEP, R., JANASEK, A., KRIZ, A., STANCEKOVA, D. (2014). Surface integrity at reaming operation by MT3 head. Manufacturing Technology, Vol. 14, No. 2, pp. 193-199. ISSN 1213-2489.

Copyright @ 2 2016. Published by Manufacturing Technology. All rights reserved. 